\title{
Environmental Biosensors: A Microbiological View
}

\author{
Juan-Carlos Gutiérrez, Francisco Amaro, Silvia Díaz, and \\ Ana Martín-González
}

\section{Contents}

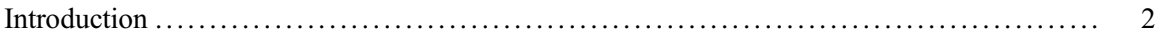

Environmental Biosensors: Why Use Microorganisms? $\ldots \ldots \ldots \ldots \ldots \ldots \ldots \ldots \ldots \ldots \ldots \ldots, \quad 4$

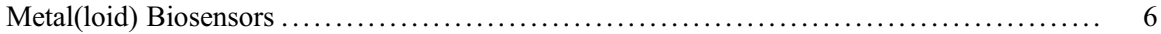

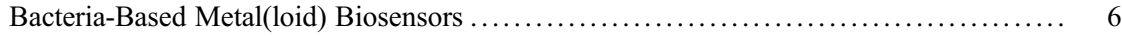

Bacterial-WCBs Based on Riboswitches .................................... 10

Eukaryotic Microorganism-Based Metal(loid) Biosensors ........................ 11

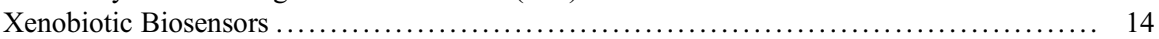

Bacteria-Based Xenobiotic Biosensors ..................................... 14

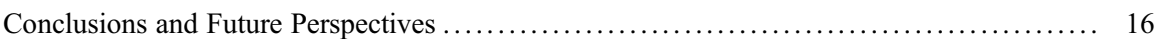

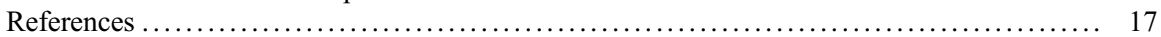

\begin{abstract}
In this mini-review, the potential of using microorganisms to design biosensors for detecting environmental pollutants is analyzed and discussed. A distinction is made between a classical biosensor (CB) and a whole-cell biosensor (WCB), emphasizing their structural components and the possibility of using whole microorganisms as their bioreceptor elements. The advantages and disadvantages of using prokaryotic microorganisms as opposed to eukaryotic microorganisms are described. Likewise, the advantages of using protozoa (ciliates) over other eukaryotic microorganisms are also shown. We analyze the current bibliography on biosensors built on microorganisms as bioreceptors of pollutant molecules, such as inorganic (metal (loid)s) or organic (xenobiotics). New trends, such as the prokaryotic riboswitches, microbial two-component systems where the pollutant can be simultaneously detected and bioremediated, along with advances in synthetic biology, are shown as promising tools in the design of environmental biosensors.
\end{abstract}

J.-C. Gutiérrez $(\triangle)$ · F. Amaro · S. Díaz · A. Martín-González

Dpto. Genética, Fisiología y Microbiología. Facultad de Biología, Universidad Complutense (UCM), Madrid, Spain

e-mail: juancar@bio.ucm.es 


\section{Keywords}

Environmental pollutants $\cdot$ Microbial biosensors $\cdot$ Metal(loid)s $\cdot$ Riboswitches

Two-component systems $\cdot$ Xenobiotics

\section{Introduction}

The Anthropocene is the geological epoch that has been proposed to succeed the Holocene (the current epoch of the Quaternary Period), due to the tremendous global impact that human activity has on all the ecosystems of our planet. During the last two centuries, the anthropogenic activity has not only caused a significant accumulation of greenhouse gases (such as $\mathrm{CO}_{2}$ ) but has also increased levels of both inorganic (metal(loid)s) and organic (xenobiotics) pollutants. This activity has serious impacts on climate (climate change we are already undergoing), biodiversity, environment, and human health.

Certain metal(loid)s, mainly those misnamed "heavy metal(loid)s," are among the most abundant, toxic, and persistent inorganic environmental pollutants (Hill 2004). Although one-third of the elements from the periodic table are essential to life, they can be toxic at high concentrations, and other nonessential elements are very toxic to living beings at very low concentrations. Diverse anthropogenic sources, such as mining and other industrial activities, have substantially increased the metal(loid) content present in the atmosphere and in many terrestrial or aquatic ecosystems (Peñuelas and Fillela 2002). Metal(loid)s can, directly or indirectly, originate reactive oxygen species (ROS) with significant alterations in proteins, nucleic acids, and lipids (Leonard et al. 2004; Valko et al. 2005). A new confirmation of the pollution of our planet is a recent report on Antarctica, in which atmospheric aerosols have been analyzed during the austral summer (2016-2017) (Caceres et al. 2019). The average mass concentration of particulate matter in some places of the coast of the Antarctica region was as high as $28.2 \mu \mathrm{g} / \mathrm{m}^{3}$. About 100 times more lead and about 600 times more chromium have been found in the air than in the soil in this region, showing a remote anthropogenic origin (Caceres et al. 2019). Organic compounds that are not part of living beings (xenobiotics) can also be an important source of environmental pollution. However, unlike metal(loid)s, many of them can be completely degraded by microorganisms to their final components $\left(\mathrm{CO}_{2}+\mathrm{H}_{2} \mathrm{O}\right)$. But, like metal(loid)s, they can be very toxic too.

Because of the ecological, sanitary, and economic consequences of these two big groups of environmental pollutants, they are considered to be priority in ecotoxicology, with the aim of minimizing the exposure to animals or humans. It is difficult to predict the global effects of increasing the different types of environmental pollutants, so there is an overriding need to develop screening methods for environmental monitoring. This need is both for the detection of pollutant compounds and monitoring of bioremediation processes of ecosystems contaminated by inorganic or organic compounds. These chemical pollutants can be measured using molecular recognition or chemical analysis, such as absorption spectroscopy, mass spectroscopy, gas chromatography, polarography, and others. However, these techniques 
require qualified personnel, present a high cost, and it is not possible to carry out in situ analysis. In addition, important ecotoxicological parameters such as bioavailability, toxicity, and genotoxicity can only be assayed using living cells (Gutierrez et al. 2015, 2017). Likewise, the most sensitive screening methods to detect pollutants are those incorporating biological components, which are used as targets for an active substance or pollutant. These detection tools that incorporate biological material or are living cells are known as biosensors or bioreporters. Therefore, we can distinguish two types of biosensors: the classical or conventional biosensors (CBs) and the whole-cell biosensors (WCBs) (Gutierrez et al. 2017).

We can define CBs as integrated bioreceptor-physicochemical transducer devices, which consist of three different parts: a bioreceptor or biological recognition element, which interacts with the pollutant molecules; a physicochemical transducer, which converts the biological response into a measurable physicochemical signal; and a microelectronic processor of this signal, which amplifies and converts it into a numeric record. The biological component can be macromolecules (enzymes, antibodies, nucleic acids, etc.) or whole cells (microorganisms or cells from multicellular organisms). We can consider four main different types of transducers: electrochemical (potentiometric or amperometric), optical (spectrophotometric or fluorometric), piezoelectric, or thermometric. To construct these $\mathrm{CBs}$, we need to have both biological and physicochemical knowledge, which frequently involves an interdisciplinary cooperation among different specialists.

The second type of biosensors, WCBs, was introduced as an alternative to CBs (Belkin 2003; Van der Meer and Belkin 2010). WCBs use prokaryotic or eukaryotic whole cells as single reporters, which incorporate both bioreceptor and transducer elements into the same cell. In general, this involves that organisms used as WCBs are experimentally modified to incorporate transducer capacity or increase their sensitivity against the pollutant. Unlike CBs, these WCBs have the advantageous feature of carrying out both in situ and ex situ analyses. When using WCBs, two different types of bioassays can be distinguished; turn off or turn on assays (Belkin 2003). Turn off bioassays are similar to standard toxicological bioassays, so the sample toxicity is evaluated from the inhibition degree of a specific cellular activity, such as growth inhibition, respiration rate, motility depletion, etc., or an unspecific cell viability. In these bioassays, the toxic concentration is proportional to the measurement of the cellular function inhibition or the cell mortality percentage. The molecular reporters used in turn off bioassays are under a constitutive gene expression (Gutierrez et al. 2017); therefore, by increasing the toxicity of the sample, cell viability is affected, and the expression of the reporter gene decreases. An example of this type of bioassay is the one marketed by the company NCIMB (UK) and called MARA (Jouanneau et al. 2017). This bioassay is based on the growth inhibition of 11 microbial strains (including 10 bacteria and 1 yeast), and cell viability is measured in microtiter plates (96 wells) by assessing of the intensity of a redox red dye which acts as a marker of cellular metabolic activity. Another possibility is to use natural bioluminescent bacteria strains (LumiMARA bioassay), such as Alivibrio fischeri or Photobacterium phosphoreum among others, so the pollutant toxic effect is assessed by the bioluminescence inhibition emitted by the cells (Jung et al. 2015). 
On the other hand, in turn on bioassays, a quantifiable molecular reporter is fused to an inducible gene promoter to be activated by a specific or group of environmental pollutants. In these WCBs, the sample toxicity or pollutant concentration is proportional to the reporter molecule gene expression. This reporter signal may reach a maximum value (critical pollutant concentration); after reaching this value, the reporter signal decreases due to the greater toxicity of the sample that can lead to cell mortality. This critical pollutant concentration value will depend on the degree of cellular resistance to the pollutant.

In general, turn off bioassays are usually quite unspecific because the reporter signal decreases as a result of a broad range of cytotoxic effects originated by very different pollutants, while turn on bioassays or CBs (using specific molecules as bioreceptors) are habitually more specific, as induction of the gene reporter or interaction with the molecular bioreceptor only takes place when the specific pollutant is present. Therefore, the WCB specificity will depend on the degree of the gene promoter specificity to be induced by an exclusive pollutant or a chemically related group of pollutants. CB specificity will depend on the specificity degree of the interaction between the bioreceptor and the pollutant. With regard to specificity, both turn on WCBs and CBs have been classified into effect- and compound-specific biosensors (Yagi 2007). Effect-specific biosensors respond to physicochemical environmental changes (e.g., $\mathrm{pH}$, temperature, or osmotic changes) or to a chemically diverse group of pollutants that induce a type of cellular stress response (e.g., oxidative stress or protein toxicity). Compound-specific biosensors respond to only one type of pollutant or compounds with similar chemical features (e.g., metal(loid)s). For some other specialists, the specificity-based classification of CBs or WCBs may be divided into three classes: class-I biosensors which only respond to a specific or exclusive pollutant by increasing the reporter signal; class-II that responds to a specific cellular stress, like oxidative stress, by increasing the reporter signal; and class-III responding unspecifically to different pollutants or environmental stressors (Gutierrez et al. 2017).

All these types of biosensors (CBs and WCBs) can be useful to detect the presence of organic or inorganic pollutant molecules in the environment. In addition, they can be also used for biomonitoring or testing the progress of a bioremediation process after detecting the chemical nature of the pollutant.

\section{Environmental Biosensors: Why Use Microorganisms?}

Microorganisms are the most abundant living beings on our planet. The estimated number of microbial genomes in the biosphere is around $10^{29}$ to $10^{30}$ (Huse et al. 2010; Kallmeyer et al. 2012), which exceeds the estimated number of galaxies $\left(10^{11}\right)$ present in our observable universe. It is between 2 and 3 orders of magnitude of the total number of animal and plant cells together on our planet. In the oceans, they represent $90 \%$ of the weight of all organisms. Therefore, they are not only quantitatively important but also qualitatively important, since they occupy all known ecosystems. This adaptation to different ecosystems has contributed to the origin of many different 
metabolisms and physiologies. Microorganisms participate in many biogeochemical cycles, with some exclusive physiologies, such as the atmospheric nitrogen fixation or the anaerobic ammonium oxidation. Microorganisms interact with both biotic and abiotic components of their ecosystems, and these interactions are essential for ecosystem functions (Shahsavari et al. 2017). They have developed different mechanisms to counteract the toxic action of inorganic and organic contaminants, and they can eat many organic pollutants of anthropogenic origin (biodegradation). This wide adaptation to different habitats makes them very useful tools when we want to design biosensors for the detection of environmental pollutants.

The complexity of the biotic and abiotic elements that make up an ecosystem makes the design of an environmental biosensor more complex than those biosensors designed for industry or clinical use. The possible interactions of the microbial biosensor (CB or $\mathrm{WCB}$ ) with unknown elements existing in a specific ecosystem, affecting the interpretation of the detection, are the main handicap of this type of biosensors. However, in spite of that, the majority of reported CB or WCB are based on prokaryotic or eukaryotic microorganisms (Verma and Singh 2005; Gutierrez et al. 2017; Metha et al. 2016). The main reason lies in the greater facility to obtain the sufficient quantity of a specific purified macromolecule (enzyme, antibody, etc.) or whole microorganisms for generating sufficiently quantifiable signal to design the biosensor. Therefore, it is easy to address using microorganisms which have, in general, a high growth rate. Microbial cultures are more manageable and cheaper than isolated enzymes, and the same enzyme, used as bioreceptor in a $\mathrm{CB}$, presents more activity in the microbial cell due to the optimal microenvironment supplied by the cell itself (Verma and Singh 2005). Many microorganisms can be easily manipulated and grown on a wide variety of different media or culture types. Likewise, many of them can be genetically modified to facilitate the biosensor design improving the sensibility (Wan et al. 2019a; Wang et al. 2014, 2015) or specificity (Wang and Buck 2014; Wang et al. 2013) to a specific environmental pollutant. In the case of WCBs, this technological capacity is essential due to necessity to incorporate the transduction capacity into the cell. Also, as stated above, microorganisms are distributed all over the planet, occupying all known ecosystems, which constitutes a great advantage if the biosensor designer is looking for a particular microbial capability to detect a specific environmental pollutant. An example of this is offered by Ralstonia metallidurans, a bacterium adapted to toxic metals (Mergeay et al. 2003), colonizing industrial sediments, soils, or wastes with a high content of metal(loid)s. From the knowledge on metal-resistant mechanisms and their regulation obtained from this bacterium and other metal-resistant microorganisms, several types of biosensors detecting metals have been designed (Diels et al. 2009; Leth et al. 2002; Tseng et al. 2014). The existence of cellular resistance mechanisms against metals or xenobiotics is really important when we want to design a WCB to detect these pollutants, because the regulatory genes and promoters involved in these mechanisms can be used for the design of the biosensor.

Among the microorganisms that can be used to design biosensors are both prokaryotes and eukaryotes. With regard to the microbial type used in WCBs to detect metal(loid)s, about $85 \%$ of these are based on genetically modified bacteria 
(Magrisso et al. 2008), while a 15\% are based on eukaryotes, and the majority of them are yeasts. However, among eukaryotic microorganisms, there is the possibility of using microbes from the three different taxonomic groups: fungi, microalgae, and protozoa (Gutierrez et al. 2017). The "eukaryotic" character is particularly important because, in general, environmental biosensors are geared toward detection of potential toxic pollutants affecting mainly eukaryotic organisms (including humans). The existence of a greater similarity of metabolism, genome, and cell organization of eukaryotic cell-based biosensors with potential organisms (plants and animals) undergoing chemical pollution makes the comparison of detection level and toxicity safer and more effective. A similar situation is found among the number of biosensors for detecting xenobiotics; prokaryotic-based biosensors exceed eukaryotic one in a ratio of approximately 10:1.

\section{Metal(loid) Biosensors}

To design metal(loid) CBs or WCBs, we can consider two basic types of microorganisms: the naturally existing or wild type and those genetically modified (anthropogenic origin). The wild-type strains usually present a peculiar feature which can be used to design the metal(loid) biosensor, such as bioluminescence, color, pigmentation, or any other characteristic that can be altered by metal(loid) toxicity. As previously indicated, these are the turn off bioassays. On the other hand, genetically modified microorganisms could be used in both turn off or turn on bioassays to design CBs or WCBs.

After an analysis of the published works, in the last 25 years, on CBs and WCBs to detect metal(loid)s, using complete microorganisms as bioreceptors (CBs) or bioreceptor-transducers (WCBs), we have seen that the number of WCBs is more than twice (78\%) as much as CBs (22\%) (Fig. 1a). It is probably due to the greater complexity of the multidisciplinary work involved in designing CBs. Regardless of the type of biosensor (CB or WCB), the frequency of using prokaryotes exceeds that of using eukaryotes. In $\mathrm{CBs}$, the prokaryote/eukaryote ratio is $59 \%: 41 \%$, while in WCBs, this ratio is $79 \%: 21 \%$ (Fig. 1b). Although eukaryotes have some advantages as WCBs (Gutierrez et al. 2015), many specialists prefer to continue using bacteria because they are easier to grow and manipulate. Among WCBs, turn on bioassays are more abundant (87\%) than turn off bioassays (13\%) (Fig. 1c). This indicates that much more specific biosensors are being searched for the detection of a given compound than those that respond to general stress caused by any environmental pollutant.

\section{Bacteria-Based Metal(loid) Biosensors}

In this section, we will review the metal(loid) biosensors designed using bacterial elements or complete bacteria. Electrochemical (amperometric or potentiometric) transducers are the majority (60\%) among bacterial CBs, in second place are optical 


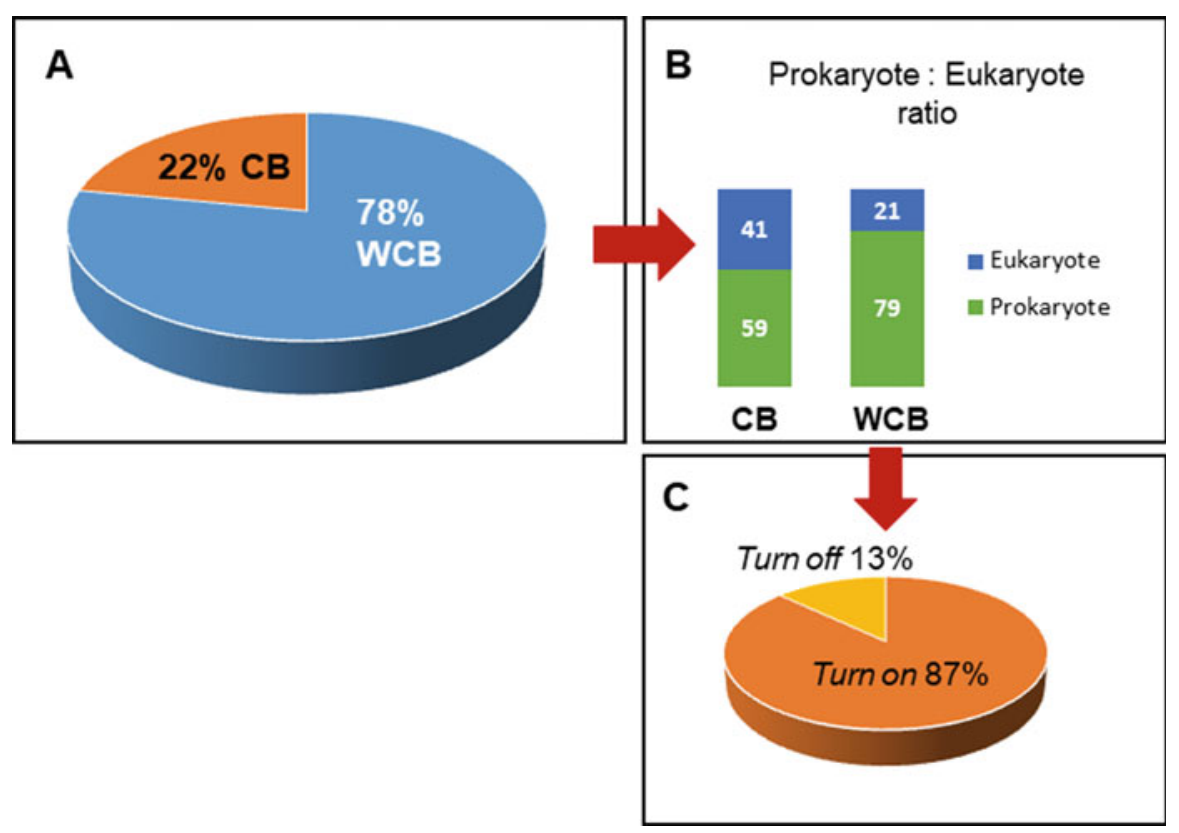

Fig. 1 Statistical analysis of metal(loid) biosensors. $C B$ classical or conventional biosensor, $W C B$ whole-cell biosensor

transducers $(30 \%)$, and in the last position are the acoustic transducers $(10 \%)$. Among bacterial WCBs, bioluminescence-based transducers have been widely used $(75 \%)$, while fluorescence and colorimetric-based transducers have been less used (about $17 \%$ and $8 \%$, respectively).

The following are some examples of CBs designed using bacteria. Immobilized whole bacteria, without genetic modifications, have been used in metal CBs, such as the bioluminescent bacterium Photobacterium phosphoreum on a cellulose nitrate membrane to detect chromium (Lee et al. 1992) or the cyanobacterium Anabaena torulosa embedded in a cellulose membrane to detect $\mathrm{Cu}(\mathrm{II}), \mathrm{Pb}$ (II), and $\mathrm{Cd}(\mathrm{II})$ (Wong et al. 2013). The presence of these toxic cations reduces the photosynthetic (cyanobacterium) or bioluminescent activity by changing the fluorescence or bioluminescence quenching of these cells. The release of photosynthetic oxygen is also inhibited under the metal(loid) presence, and the oxygen reduction can be detected by an oxygen electrode (Shing et al. 2008). Bacterial enzymes have been also used to design metal $\mathrm{CBs}$, under the assumption that toxic metals can inhibit the enzyme activity and show a direct correlation between the enzyme inhibition rate and metal toxicity. Enzymes, such as alkaline phosphatase, glucose oxidase, or urease, among others, have been used to detect $\mathrm{Cd}(\mathrm{II}), \mathrm{Pb}(\mathrm{II}), \mathrm{Zn}(\mathrm{II}), \mathrm{Ni}(\mathrm{II})$, or $\mathrm{Co}(\mathrm{II})$ (Berezhetskyy et al. 2008), in addition to $\mathrm{Hg}(\mathrm{II}), \mathrm{Ag}(\mathrm{I}), \mathrm{Cu}$ (II), and $\mathrm{Fe}(\mathrm{III})$ (Guascito et al. 2008; Ilangovan et al. 2006; Samphao et al. 2012). 
Genetically engineered bacteria have been mainly used to design metal WCBs. Here we describe some of the most relevant. Some WCBs presumably specific to one or two metals have been reported. To detect As(III), a sensing construct formed by the $\operatorname{ars} R$ gene promoter (arsenic-sensitive promoter) from Escherichia coli fused to $m t r B$ gene (involved in metal reduction pathway) from Shewanella oneidensis, a bacterium with great capacity to reduce metal ions and living in environments with and without oxygen. Accordingly, the output signal is bioelectrochemical (Webster et al. 2014). Another WCB with a high specificity to detect As(III) is also based on the promoter of the operon ars from $E$. coli, with a $P_{\text {ars }}::$ ars $R$ construct fused with the reporter gene $g f p$, so the signal measurement is fluorescent (Li et al. 2015). To improve the sensitivity of this WCB, the authors carried out directed evolution experiments, where mutants were selected after three generations obtaining strains with a 12-fold increase of their response to As. Likewise, this WCB was tested with environmental samples contaminated with As, which means a positive validation for this environmental biosensor. Other similar constructs based on the ars promoter and the $\operatorname{ars} R$ regulator gene, fused with different fluorescent or luminescent reporter genes, have been designed (Huang et al. 2015; Hu et al. 2010; Jia et al. 2019; Merulla and van der Meer 2016; Preveral et al. 2017; Sharma et al. 2013; Wan et al. 2019b; Wang et al. 2014, 2015).

Several recombinant strains from both Gram-positive (Staphylococcus aureus and Bacillus subtilis) and Gram-negative (E. coli and Pseudomonas fluorescens) bacteria have been constructed to express bioluminescence reporter genes (luciferase system) to be used as metal WCBs (Gutierrez et al. 2017; Ivask et al. 2009). Both turn off and turn on bioassays have been carried out using different bacterial strains of which five for detecting $\mathrm{Cu}$ (II) or $\mathrm{Hg}$ (II) were target metal specific, whereas eight other strains showed a lower specificity level, responding to diverse metals (Cd(II), $\mathrm{Hg}(\mathrm{II}), \mathrm{Zn}(\mathrm{II})$, and $\mathrm{Pb}(\mathrm{II})$ ) (Gutierrez et al. 2017). Other multi-metal(loid) response WCBs using E. coli as bacterial recipient are those reported by Branco et al. (2013), Hou et al. (2015), and Kim et al. (2016). Another E. coli-based WCB for detecting chromate in environmental samples use the plasmid pCHRGFP1 containing the construct $P_{c h r B}: \because G F P$ (fluorescence signal) and presumably do not respond to other metal(loid)s (Branco et al. 2013). The promoter $P_{c h r B}$ was isolated from the Gram-negative aerobic bacterium Ochrobactrum tritici, which has been also used as WCB by these authors. Other nonclassical bacterial species used as WCB are the Gram-negative Salmonella enterica, which, like other E. coli-based WCBs, hosting the construct $P_{\text {golB }}: \because G F P$, has been used to detect Au (Cerminati et al. 2011). The soil bacterium $R$. metallidurans has been used as a WCB (turn on bioassay) to detect $\mathrm{Cr}$ (II) by using the lux reporter gene system (Corbisier et al. 1999). Another strain of $R$. metallidurans has been used as WCB to detect Ni(II) and Co(II) in soil samples, after transformation with the megaplasmid pMOL1550 containing the chr operon promoter (Ni(II) and $\mathrm{Co}(\mathrm{II})$ resistance system) (Tibazarwa et al. 2000) fused to lux reporter gene (Tibazarwa et al. 2001).

A WCB, to detect $\mathrm{Cd}(\mathrm{II})$ and $\mathrm{Zn}(\mathrm{II})$, has been designed using the $\operatorname{cad} A$ gene promoter from S. aureus (Yoon et al. 1991) fused to the firefly luciferase reporter gene into the plasmid pT0024, using cell chassis of both $S$. aureus and B. subtilis 
(Tauriainen et al. 1998). In the cyanobacterium Synechococcus, the smt locus contains $s m t B$ (a trans-acting repressor) and the metal-regulated smtA (encoding a metallothionein). Depending on the environmental bioavailability of metal(loid)s, $\operatorname{smt} B$ gene controls the gene expression of smtA (Erbe et al. 1996). Based on this system and using the same cyanobacterium, a multi-metal(loid) response $\mathrm{WCB}$ has been designed, harboring the plasmid construct $S m t: \operatorname{lu} x C D A B E$. This WCB presents a linear response to several metals, such as $\mathrm{Cd}(\mathrm{II}), \mathrm{Cu}(\mathrm{II}), \mathrm{Zn}(\mathrm{II}), \mathrm{Co}(\mathrm{II}), \mathrm{Hg}(\mathrm{II})$, and $\mathrm{Ag}(\mathrm{I})$, with sensitivity ranking of $\mathrm{Hg}>\mathrm{Cu}>\mathrm{Ag}>\mathrm{Co}>\mathrm{Zn}>\mathrm{Cd}$ (Martin-Betancor et al. 2015).

Other bacterial genetic constructs have improved both specificity and metal detection and quantification (Bernard and Wang 2017; Wan et al. 2019b; Wang et al. 2013). For instance, a specific $\mathrm{Cu}-\mathrm{WCB}$ based on an E. coli strain containing a plasmid with the construct $P_{\text {copA }}: G F P$ has been reported (Kang et al. 2018). This bacterial strain has a deletion affecting the $\operatorname{cop} A$ gene, which is involved in cellular copper export, so this mutation makes this strain more sensitive to $\mathrm{Cu}(\mathrm{II})$ than the wild type. Under small $\mathrm{Cu}$ amounts $(\mu \mathrm{M})$, this $\mathrm{WCB}$ responds specifically to $\mathrm{Cu}$, no responding to other metals.

Dual sensing WCBs are another very useful monitoring possibility as it can detect two different metals with different sensitivity. A dual sensing WCB based on E. coli has been designed to detect bioavailable $\mathrm{As}(\mathrm{III})$ or $\mathrm{As}(\mathrm{V})$ and $\mathrm{Cd}(\mathrm{II})$ in polluted soil samples (Yoon et al. 2016a). It carries two different genetic constructs: $P_{\text {ars }}:$ : $m$ Cherry (a monomeric red fluorescent protein) and $P_{z n t}: \because e G F P$ (enhanced GFP version) or the cross-combination fusions $P_{\text {ars }}:: e G F P$ and $P_{z n t}:: m$ Cherry. The first construct responds to $\mathrm{As}(\mathrm{III})$ mainly, but also to $\mathrm{As}(\mathrm{V})$, while the second one responds to $\mathrm{Cd}(\mathrm{II})$. This dual $\mathrm{WCB}$ was seen to respond mainly and simultaneously As and Cd, but no against other metal(loid)s (Yoon et al. 2016a).

In ecotoxicology, it is important to monitor pollutants both before and during its remediation. A novel strategy to test arsenic bioavailability in soil samples by direct (in vivo) or indirect (in vitro) measurement using an E. coli-based WCB has been reported by Yoon et al. (2016b). As previously reported, the plasmid construct has $P_{\text {ars }}:: e G F P$, which shows a high specificity to As. This WCB was applied to detect $\mathrm{As}(\mathrm{III})$ and $\mathrm{As}(\mathrm{V})$ in both laboratory and polluted soil samples. The authors (Yoon et al. 2016b) also described a standardized protocol to measure bioavailable As in soil samples. Hence this WCB was seen to be a useful tool to evaluate the efficiency of soil arsenic remediation processes.

Likewise, metal(loid) environmental pollution monitoring is as important as bioremediation of the pollutant. An ideal situation would be to have a biosensor to detect a specific pollutant but also to bioremediate that same pollutant. These are WCBs based on two-component regulatory systems. The bacterial two-component systems have been engineered as synthetic biotechnological platforms for both monitoring and bioremediation purposes (Ravikumar et al. 2017). These WCBs simultaneously sense and remove (by bioadsorption) metals from the environment. For instance, detection and removal of $\mathrm{Cu}^{2+}$ ions in the E. coli surface have been achieved using the two-component system CusSR which allows for exogenous copper detection via membrane-associated kinase (Ravikumar et al. 2011). The CusSR two-component is a regulatory system for copper homeostasis in E. coli. 
The gene ompC codes an outer membrane pore protein (porin), which is induced by high osmolarity and temperature. CusSR system activates the expression of CusCFBA operon, and $C u s C$ gene encodes a copper-binding peptide (CBP). Authors (Ravikumar et al. 2011) obtained a bacterial adsorption system constructed by the integration of chimeric OmpC::cusC under the $P_{\text {cusC }}$ promoter located in the plasmid pCC1056, to respond to and adsorb exogenous copper. Other two-component regulatory system-based microbial biosensors coupled with bioadsorption have been designed for metal sensing and bioremediation or biorefinery of some organic compounds (Ravikumar et al. 2017).

\section{Bacterial-WCBs Based on Riboswitches}

Riboswitches are regulatory elements (noncoding sequences) within a mRNA molecule, able to bind different metabolites (purines and derivatives, cofactors, amino acids) and metal ions ( $\mathrm{Mg}(\mathrm{II}), \mathrm{Ni}(\mathrm{II}), \mathrm{Co}(\mathrm{II}))$ as ligands. They regulate mRNA expression by transcription termination/anti-termination or translation inhibition or activation. The mRNA regulatory or switching sequence is most often located in the $5^{\prime}$-UTR, as a stretch of RNA preceding the translation starting site, although in some eukaryotic mRNAs, the riboswitch regulates splicing at the 3'-UTR (Edwards and Batey 2010). Riboswitches have two domains; the aptamer domain (acting as a receptor that specifically binds a ligand) and the expression platform or coding region (ORF: open reading frame). A riboswitch can adopt different secondary structures effecting gene expression depending on whether a target ligand is bound. When ligand is not bound, the expression platform incorporates the switching sequence into an anti-terminator stemloop, and transcription starts through the mRNA coding region. But, when ligand binds, the switching sequence is incorporated into the aptamer domain, and the expression platform folds into a terminator stem-loop, inducing transcription stop.

In addition, mRNA translation activated by riboswitches (Serganov and Nudler 2013). The expression of ORFs can be repressed by sequestration of the ribosome entry site, blocking the translation initiation. When a ligand is attached to a riboswitch, the formation of an anti-sequester hairpin can be facilitated, opening the entrance to the ribosome and initiating the translation of the mRNA.

Riboswitches are very common in Gram-positive bacteria, where they control the expression of around $4 \%$ of the genes (Lünse et al. 2011). Recently (Machtel et al. 2016), riboswitches have been considered as a new tool for WCB design. We can select a riboswitch responding to a specific metabolite or ligand through the in vitro selection process known as SELEX (systematic evolution of ligands by exponential enrichment). This experimental methodology originates the aptamer domain of a riboswitch responding to almost any metabolite (including metals). These riboswitches bind ligands even in very low concentrations in a dose-dependent manner (Fig. 2). Although it is known that riboswitches binding metal cations and anions exist (McCown et al. 2017; Wedekind et al. 2017), a WCB has not yet been built to 


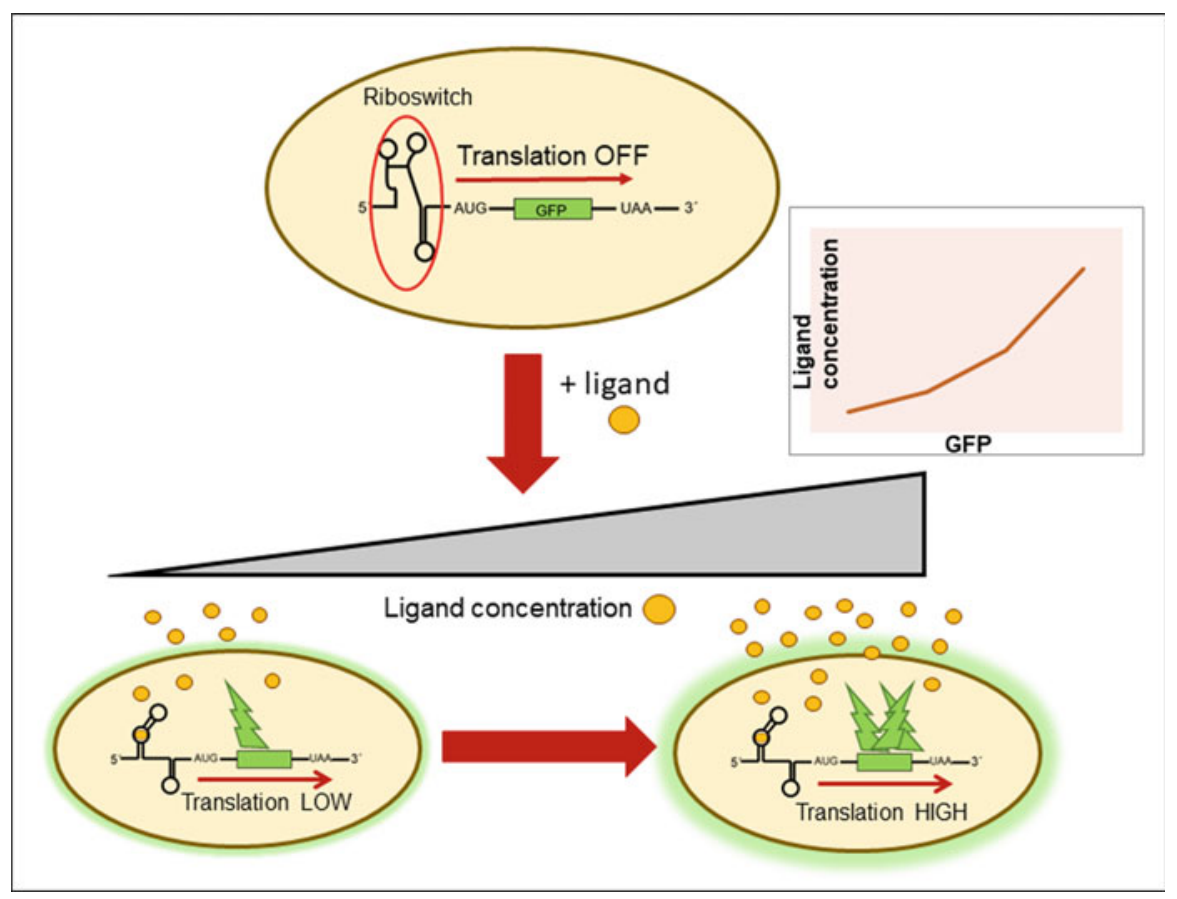

Fig. 2 Schematic of a riboswitch-based cell biosensor and its response to an increasing ligand concentration. GFP green fluorescent protein, $A U G$ start codon, $U A A$ stop codon

detect metal(loid) based on these molecular sensing systems. However, we know the existence of WCBs to detect organic compounds (drugs or xenobiotics), which will be discussed in the corresponding section. Riboswitches as molecular tools to design WCBs for detecting both metal(loid)s or xenobiotic compounds appear as a promising area in biosensorization of environmental pollutants (Findei et al. 2017).

\section{Eukaryotic Microorganism-Based Metal(loid) Biosensors}

As previously indicated, metal WCBs based on eukaryotic microorganisms are more scarce than those using prokaryotic ones. The main eukaryotic microorganisms used to design both CBs or WCBs to detect metal(loid)s in polluted environments have been selected among microalgae, fungi (including yeasts), and ciliated protozoa (Gutierrez et al. 2017). To detect metal(loid)s, all reported CBs using eukaryotic microorganisms are electrochemical, while an $83 \%$ of WCBs are based on bioluminescence and the rest (17\%) use fluorescence. The great majority of eukaryotic microbial biosensors use yeasts as the cellular component (yeast-based WCBs are reviewed by Adeniran et al. 2015). Second are microalgae (mainly genera Chlorella 
and Chlamydomonas), followed by protozoa which is represented only by the ciliate Tetrahymena thermophila (Amaro et al. 2011, 2014).

The yeast-model Saccharomyces cerevisiae is the most widely used eukaryotic microorganism in diverse biological areas, especially in genetic and bioengineering, which leads certain researchers (Walmsley and Keenan 2000) to consider that they can be good candidates to design biosensors for natural polluted environmental samples. However, like bacteria, yeasts have a cell wall protecting the cell and acting as a selective barrier for very different molecules (including substrates used by the biosensor transducer system in WCBs), which makes the transducer signal difficult to be efficiently emitted. For this reason, in some occasions, it is necessary to increase the cell permeability before using them as WCBs or bioreceptor in CBs, which constitutes an additional disadvantage. Mutants with enhanced cell permeability could be used for this purpose (Terziyska et al. 2000; Walmsley and Keenan 2000).

The majority of yeast-based biosensors use the CUP1 promoter of the cup 1 gene, encoding a copper-binding metallothionein (CUP1), which are used as biosensors for detecting copper. Some examples are given below. A recombinant $S$. cerevisiae strain has been used to design an amperometric CB (Lehmann et al. 2000) to detect $\mathrm{Cu}(\mathrm{II})$. Another amperometric $\mathrm{CB}$ using other different recombinant $S$. cerevisiae strain to detect $\mathrm{Cu}(\mathrm{II})$ has been constructed using the lacZ reporter gene (Tag et al. 2007). A biosensor to detect $\mathrm{Cu}(\mathrm{II})$ ions in water samples using genetically modified $S$. cerevisiae within immobilized alginate beads and based on the CUPI promoter has been elaborated by Vopálenská et al. (2015). To validate this WCB, authors compare the $\mathrm{Cu}(\mathrm{II})$ measurements by the biosensor from urban water samples with those results obtained by standard laboratory assays using the same water samples. The transcriptional activator protein AceI present in $S$. cerevisiae has been used to control the expression of the reporter gene $g f p$ (Shetty et al. 2004). When Cu(II) ions are present, the AceI protein activates the cupl gene promoter fused with the $g f p$ gene. This WCB is not selective for $\mathrm{Cu}$ (II) because it also responds to $\mathrm{Ag}$ (II) (Shetty et al. 2004). Another similar WCB, also for $\mathrm{Cu}(\mathrm{II})$ detection, has been constructed using the same CUP1 promoter but with the luciferase reporter gene, showing a similar detection level for this metal (Roda et al. 2011).

This yeast has been also used to design biosensor for detecting other metals. For instance, the Cd-inducible SEO1 promoter from the yeast Hansenula polymorpha was fused to $g f p$ gene, which was introduced in $S$. cerevisiae cells to detect $\mathrm{Cd}(\mathrm{II})$ ions (Park et al. 2007). This reporter construct is not specific to Cd(II) because it is also inducible by As(III). Likewise, the SEOI promoter from S. cerevisiae revealed that it is inducible by multiple metal ions with sensitivity rank of $\mathrm{As}(\mathrm{III})>\mathrm{Cd}(\mathrm{II})>\mathrm{Hg}(\mathrm{II})$, hence also unspecific for $\mathrm{Cd}(\mathrm{II})$. A WCB based on an engineered $S$. cerevisiae strain responds to several metal(loid)s (Radhika et al. 2005). This yeast strain harbors a plasmid with the human $C R E B B P$ gene (encoding a binding protein to $C R E B$ gene, a cAMP response element binding that acts as a transcription factor) and the construct of $P_{c r e b}: \because g f p$. When the yeast sensor is under the toxic metal exposure, a stress pathway is activated and cAMP levels increase. cAMP activates the CREBBP gene expression, and, in turn, the CREB protein activates the CREB promoter to express the GFP reporter gene to generate the output signal. 
Microalgae are also significant microorganisms to design biosensors for aquatic ecosystem (Kröger and Law 2005). Chlorella vulgaris immobilized cells have been used to design a conductive $\mathrm{CB}$ based on the alkaline phosphatase activity inhibition to detect Cd(II) ions (Chouteau et al. 2004). This same microalga was used as a WCB for detecting $\mathrm{Cd}(\mathrm{II})$ in a water suspension or immobilized cells in a translucent silica matrix. The $\mathrm{Cd}$ (II) toxicity affected the photosynthetic activity (turn off bioassay) resulting a quenching of cell fluorescence (Nguyen-Ngoc et al. 2009). For monitoring $\mathrm{Cu}$ (II) in water supplies, the Chlorophyta Dictyosphaerium chlorelloides has been used with an optical fiber coupled to the cellular flow or a microtiter plate reader (PeñaVazquez et al. 2010). The flagellar motility of Chlamydomonas reinhardtii has been used to design an electrochemical biosensor to detect $\mathrm{Cu}$ (II) or $\mathrm{Ni}$ (II) (Shitanda et al. 2005).

Unlike yeasts, the lack of usable genetic tools for bioengineering many microalgae has likely limited the construction of WCBs, perhaps the main reason to use wild-type strains as the bioreceptor elements in both CBs and WCBs. Although $C$. reinhardtii is an exception, this microalga has not yet been genetically modified to design biosensors for environmental metal(loid) monitoring, even though diverse studies have already been carried out to assess metal toxicity with this microorganism (Aksmann et al. 2014; De Schamphelaere et al. 2014). Considering microalgae present sufficient qualities to be selected as good potential metal(loid) biosensors, we can conclude that this micro-algal biotechnological aspect has not yet been adequately exploited.

Ciliated protozoa have been extensively used in ecotoxicological studies (Gutierrez et al. 2008). With respect to the cell sensitivity level and biosensing toxicity for humans, ciliates have, at least, two additional advantages with regard to other microorganisms. In first place, unlike bacteria, yeasts, or microalgae, ciliates do not have a cell wall in their growth vegetative stage. As it has been indicated in previous reviews (Gutierrez et al. 2015, 2017), microorganisms with a cell wall to be used as WCB or bioreceptor elements of CBs have an important limitation since the selective diffusion of molecules through their cell walls results in a lower emission or less effective cell response to pollutants. In several cases, to address this barrier, cells have had to be permeabilized by physicochemical or enzymatic methods. In addition to this difficulty, the presence of a cell wall may involve a non-specific, uncontrolled metal(loid) biosorption process, which may affect the real cellular response to the external metal concentration, when cells are not used as a biosorption-based biosensor. This problem might be solved using ciliates in the biosensor designing, because the absence of cell walls leads to a high sensitivity and rapid response to a variety of environmental pollutants (Martin-Gonzalez et al. 1999; Gutierrez et al. 2003).

In second place, ciliates are eukaryotic cells with an animal biology, which present a series of metabolic traits more similar to those of human cells than bacteria, microalgae, or even yeasts. The genome sequencing projects of two ciliate models, Tetrahymena thermophila and Paramecium tetraurelia (Aury et al. 2006; Eisen et al. 2006), have shown that they share a higher degree of functional conservation with human genes than do other eukaryotic microbial models. For instance, humans and T. thermophila share more ortholog genes with each other (about 2280) than are 
shared between humans and the yeast $S$. cerevisiae (Eisen et al. 2006). Likewise, the scores of $P$. tetraurelia proteins against human proteins are the highest with regard to the scores of yeast proteins to human proteins, suggesting that Paramecium proteins are most similar to human proteins (Sperling et al. 2002). These similarities with human biology makes it more reasonable to use these eukaryotic microorganisms in ecotoxicological studies (Gutierrez et al. 2008, 2011) or to design biosensors for monitoring toxicity of metal(loid)s or xenobiotic compounds for humans, in aquatic or terrestrial ecosystems.

Unfortunately, there are few currently published ciliate-based biosensors. Only the ciliate T. thermophila has been used to design WCBs for metal(loid)s, which have been validated using natural (soil and aquatic) metal polluted environmental samples (Amaro et al. 2011). These turn on WCBs have been designed using promoters of MTT1 or MTT5 metallothionein genes from this ciliate and the firefly luciferase as the reporter gene. These lineal constructs were then introduced into macronuclear genome by biolistic transformation (Amaro et al. 2011). A second type of T. thermophila WCB has been designed using $M T T 1$ gene promoter and the $g f p$ reporter gene fused to the MTT1 or MTT5 complete ORF into a plasmid (Amaro et al. 2014). A comparative analysis of both metal WCBs is reported in Gutierrez et al. (2017).

Although the three types of eukaryotic microorganisms (yeasts, microalgae, or protozoa) can be used to design both CBs or WCBs for metal(loid) environmental monitoring, they all have certain advantages and disadvantages, which have been previously discussed (Gutierrez et al. 2017).

\section{Xenobiotic Biosensors}

Like metal(loid) biosensors, xenobiotic biosensors can be designed using both wildtype and genetically modified microorganisms. The great diversity of microbial capabilities to biodegrade or biotransform xenobiotics is the basis to design biosensors to detect these toxic compounds. In the design of these biosensors, prokaryotes predominate over eukaryotes probably due to the greater capacity of bacteria to degrade very different organic compounds compared to eukaryotes. Unlike what happens with metal biosensors, CBs to detect xenobiotics are the majority (88\%) against WCBs (12\%). The common physicochemical transducer used in these xenobiotic CBs is electrochemical. Due to the scarcity of xenobiotic biosensors based on eukaryotic microorganisms, in this section, we will explore exclusively those biosensors based on prokaryotes.

\section{Bacteria-Based Xenobiotic Biosensors}

Like metal(loid) biosensors, bacterial two-component systems have been used to design xenobiotic biosensors. Aromatic compounds are very abundant organic environmental pollutants. Many bacteria can feed on these organic compounds as a carbon source. Several two-component regulatory systems are involved in the 
catabolism of aromatic compounds, by inducing and activating the corresponding aromatic metabolizing pathway. Pseudomonas putida degrades toluene and other benzene derivatives; the first four steps of the catabolic pathway involve the sequential action of seven tod genes, which form part of the tod operon (Zylstra et al. 1988). This operon can be induced by different aromatic compounds (toluene, xylene, benzene, ethylbenzene) and is modulated by a two-component regulatory system. Engineered microbial biosensors based on bacterial two-component systems, like $P$. putida among others, can be very useful to construct synthetic biotechnology platforms for monitoring, bioremediation, and biorefinery (Ravikumar et al. 2017).

Recently, microbial fuel cell-based biosensors have attracted great interest due to their sustainability, low cost, and applications including anaerobic digestion process monitoring or water quality detection (Zhou et al. 2017). The voltage originated by microbial fuel cells is correlated with the amount of a specific substrate, presenting a linear correlation. Several studies have reported that these biosensors can detect organic compounds, such as p-nitrophenol, formaldehyde, or the antibiotic levofloxacin. An important limitation of these biosensors is their low sensitivity, as the detection range is above the currently allowed contaminant level. Therefore, an improvement in sensitivity will be necessary for their widespread application.

Riboswitch-based WCB for bisphenol A (BPA), a known endocrine disruptor and potential carcinogen present in plastics, food packaging, and drinking water supplies, has been tried in E. coli (Zorawski et al. 2016). TetA is a transporter protein that pumps tetracycline out of the cell, making the cell resistant to this antibiotic. In addition, this protein allows $\mathrm{Ni}$ (II) to enter the cell, inhibiting growth. tetA gene expression is regulated by a riboswitch. The construct $P_{\text {Teta }}:: t e t A: \because g f p$ was introduced into a plasmid, and then the aptamer domain of the riboswitch was replaced, by PCR, with 40 random bases to generate plasmid libraries. E. coli was transformed using these plasmids such that each bacterium harbored only a copy of the plasmid library. A selection was carried out to identify riboswitches expressing TetA-GFP only in response to BPA. Unfortunately, the authors failed to produce a significant increase in output fluorescence under the presence of BPA compared to control (without ligand) (Zorawski et al. 2016). However, this pioneering work could be a first step in the future construction of WCBs using riboswitches to detect xenobiotic molecules.

A selection of research studies reporting xenobiotic biosensors is summarized as follows. CBs using different bacterial species (Pseudomonas, Sphingomonas, Ralstonia, and Rhodococcus) immobilized onto a Clark-type oxygen electrode were tested for monitoring the cellular degradation capacity and detection of several xenobiotic compounds especially their chlorinated derivatives (chlorophenols, chlorobenzoates, PCBs, among others) (Beyersdorf-Radeck et al. 1998). This study showed that each bacterium prefers selectively a type of substrate, suggesting for each xenobiotic biosensor a specific type of bacteria should be selected in advance.

A bioluminescent $E$. coli strain carrying the lux operon and the promoter region of the pgi gene (encoding the glucose-6-phosphate isomerase), which responds to oxidative stress, was used for the construction of a bioluminescent WCB (Niazi et al. 2008). This biosensor is designed on the basis that xenobiotics can induce cell 
damage by oxidative stress, such as the herbicide paraquat (Diaz et al. 2016), causing oxygen free radicals.

The lin $A$ gene encoding the enzyme $\gamma$-hexaclorocyclohexane dehydrochlorinase, involved in biodegradation of the pesticide lindane, was cloned and overexpressed in E. coli. Subsequently, cells from this lindane biodegradating strain were immobilized on polyaniline film. The hydrochloric acid generation from the lindane biodegradation by the recombinant $E$. coli cells led to a change in the conductivity of the polyaniline film, which was monitored amperometrically (Prathap et al. 2012). This CB detects lindane at a concentration of one part per trillion, and was selective to all lindane isomers, but did not respond to other aliphatic, aromatic chlorides or the end product of lindane degradation.

Another possible technical approach for designing WCBs to detect xenobiotics is the use of immobilized cells in microplates. Whole cells of the bacterium Sphingomonas sp., which hydrolyzes the methyl parathion (an organophosphate pesticide and insecticide) into p-nitrophenol (yellow-colored product), were immobilized onto the surface of the polystyrene microplate wells. Para-nitrophenol was detected by a colorimetric method (microplate reader) (Kumar and D'souza 2010). Microplate-based biosensors constitute a convenient system to detect multiple numbers of samples in a single platform.

Organophosphate pesticides are very serious environmental pollutants. Amperometric, potentiometric, and optical CBs based on engineered microorganisms expressing organophosphate-hydrolyzing enzymes, either located intracellularly or anchored to the cell surface, have been designed to detect these dangerous pesticides (Lei et al. 2007). The advantages of using microorganisms over purified enzymes are lower cost and simpler construction.

There are many other examples of potential biosensors for detecting xenobiotics, although most are based on the ability of bacteria to degrade or biotransform these molecules.

\section{Conclusions and Future Perspectives}

1. In general, microorganisms used as whole cells or cell factories to design biosensors (CBs or WCBs) for detecting environmental pollutants present greater advantages than using molecules (such as enzymes). In addition, eukaryotic microorganisms have certain advantages over prokaryotic microorganisms, because the comparative analysis with multicellular organisms (including humans) is more reliable than using bacteria.

2. Likewise, protozoa, and mainly ciliates, present a great potential to design both WCBs and CBs, mainly due to its greater sensitivity to environmental pollutants without a cell wall and also due to their greater resemblance to human cells.

3. In almost all prokaryotic and many eukaryotic microorganisms, the presence of a cell wall is a hurdle or inconvenience in the design of a biosensor, because it could hinder permeability or retain (biosorption) pollutant molecules. In addition, using substrate-dependent reporters, substrates must cross the cell wall to reach the 
cytoplasm, where the enzymatic reaction takes place. Therefore, it is sometimes necessary to pre-treat the cell to make it permeable to the molecule.

4. With respect to metal(loid) contaminants, the sensitivity of the biosensor is more important than its level of specificity to the target metal. This is because, in the real world, anthropogenic contamination by metal(loid)s is complex with the presence of several metal(loid)s.

5. In general, many CBs or WCBs are exclusively tested in the laboratory, under strictly controlled conditions, but very few of those published are validated using natural samples from metal(loid) or xenobiotic polluted environments. Due to this lack of essential experimentation, to evaluate a biosensor's usefulness for detecting an environmental pollutant, many of the biosensors considered as specific for detecting a certain pollutant molecule are not really so. It is due to the presence of other unknown organic or inorganic molecules, from the soil or aquatic ecosystem, which can interact with the bioreceptor element and interfere with the response. This point is really important for designing functional biosensors to be used in polluted environments in the real world.

6. The future development of biosensors (CBs or WCBs) for the monitoring of environmental pollutants could be developed on the basis of three, still little explored, experimental routes:

(a) A greater and more intense exploration of prokaryotic riboswitches, to experimentally select those that interact with metals or xenobiotics. This exploration should also extend to eukaryotic microorganisms.

(b) Enabling the same biosensor with both capabilities: the monitoring of the environmental pollutant and its bioremediation. For this purpose, two-component systems could be essential parts in the design of these bifunctional systems (biosensor-bioremediator).

(c) A synthetic biology approach. This could facilitate the design of environmental biosensor (mainly WCBs) with multi-input systems based on two or more regulatory gene promoters in the same genetic construct, thereby increasing the capacity of the biosensor to detect simultaneously several different organic or inorganic pollutants in the same environmental sample (Wang et al. 2013, 2014).

\section{References}

Adeniran A, Sherer M, Tyo KEJ (2015) Yeast-based biosensors: design and applications. FEMS Yeast Res 15:1-15

Aksmann A, Pokora W, Bascik-Remisiewicz A et al (2014) Time-dependent changes in antioxidative enzyme expression and photosynthetic activity of Chlamydomonas reinhardtii cells under acute exposure to cadmium and anthracene. Ecotoxicol Environ Saf 110C:31-40

Amaro F, Turkewitz AP, Martin-Gonzalez A et al (2011) Whole-cell biosensors for detection of heavy metal ions in environmental samples based on metallothionein promoters from Tetrahymena thermophila. Microb Biotechnol 4:513-522

Amaro F, Turkewitz AP, Martin-Gonzalez A et al (2014) Functional GFP-metallothionein fusion protein from Tetrahymena thermophila: a potential whole-cell biosensor for monitoring heavy 
metal pollution and a cell model to study metallothionein overproduction effects. Biometals 27:195-205

Aury JM, Jaillon O, Duret L et al (2006) Global trends of whole-genome duplications revealed by the ciliate Paramecium tetraurelia. Nature 444:171-178

Belkin S (2003) Microbial whole-cell sensing systems of environmental pollutants. Curr Opin Microbiol 6:206-212

Berezhetskyy AL, Sosovska OF, Durrieu C et al (2008) Alkaline phosphatase conductometric biosensor for heavy metal ions determination. IRBM 29:136-140

Bernard E, Wang B (2017) Synthetic cell-based sensors with programmed selectivity and sensitivity. In: Rasooly A, Prickril B (eds) Biosensors and biodetection: methods and protocols. Methods in molecular biology, vol 1572. Springer, New York, pp 343-363

Beyersdorf-Radeck B, Karlson KR, Bachmann TT et al (1998) Screening of xenobiotic compounds degrading microorganisms using biosensor techniques. Microbiol Res 153:239-245

Branco R, Cristovao A, Morais PV (2013) Highly sensitive, highly specific whole-cell bioreporters for the detection of chromate in environmental samples. PLoS One 8:e54005

Caceres JO, Sanz-Mangas D, Manzoor S et al (2019) Quantification of particulate matter, tracking the origin and relationship between elements for the environmental monitoring of the Antarctic region. Sci Tot Env 665:125-132

Cerminati S, Soncini FC, Checa SK (2011) Selective detection of gold using genetically engineered bacterial reporters. Biotechnol Bioeng 108:2553-2560

Chouteau C, Dzyadevych S, Chovelon JM et al (2004) Development of novel conductometric biosensors based on immobilized whole cell Chlorella vulgaris microalgae. Biosens Bioelectron 19:1089-1096

Corbisier P, van der Lelie D, Borremans B et al (1999) Whole cell-and protein-based biosensors for the detection of bioavailable heavy metals in environmental samples. Anal Chim Acta 387:235-244

De Schamphelaere KAC, Nys C, Janssen CR (2014) Toxicity of lead (Pb) to freshwater green algae: development and validation of a bioavailability model and inter-species sensitivity comparison. Aquat Toxicol 155:348-359

Diaz S, Martin-Gonzalez A, Cubas L et al (2016) High resistance of Tetrahymena thermophila to paraquat: mitochondrial alterations, oxidative stress and antioxidant genes expression. Chemosphere 144:909-917

Diels L, Van Roy S, Taghavi S et al (2009) From industrial sites to environmental applications with Cupriavidus metallidurans. A Leeuwenhoek 96:247-258

Edwards AL, Batey RT (2010) Riboswitches: a common RNA regulatory element. Nat Educ 3(9):9

Eisen JA, Coyne RS, Wu M et al (2006) Macronuclear genome sequence of the ciliate Tetrahymena thermophila, a model eukaryote. PLoS Biol 4:e286

Erbe JL, Adams AC, Taylor KB et al (1996) Cyanobacteria carrying an smt-lux transcriptional fusion as biosensors for the detection of heavy metal cations. J Ind Microbiol 17:80-83

Findei BS, Etzel M, Will S et al (2017) Design of artificial riboswitches as biosensors. Sensors 17:1-28. https://doi.org/10.3390/s17091990

Guascito MR, Malitesta C, Mazzotta E et al (2008) Inhibitive determination of metal ions by an amperometric glucose oxidase biosensor: study of the effect of hydrogen peroxide decomposition. Sens Actuators B Chem 131:394-402

Gutierrez JC, Martin-Gonzalez A, Diaz S et al (2003) Ciliate as potential source of cellular and molecular biomarker/biosensors for heavy metal pollution. Eur J Protistol 39:461-467

Gutierrez JC, Martin-Gonzalez A, Diaz S et al (2008) Ciliates as cellular tools to study the eukaryotic cell-heavy metal interactions. In: Brown SE, Welton WC (eds) Heavy metal pollution. Nova Science Publishers, New York, pp 1-44

Gutierrez JC, Amaro F, Diaz S et al (2011) Ciliate metallothioneins: unique microbial eukaryotic heavy-metal-binder molecules. J Biol Inorg Chem 16:1025-1034

Gutierrez JC, Amaro F, Martin-Gonzalez A (2015) Heavy metal whole-cell biosensors using eukaryotic microorganisms: an updated critical review. Front Microbiol 6:1-8 
Gutierrez JC, Amaro F, Martin-Gonzalez A (2017) Microbial biosensors for metal(loid)s. In: CravoLaureau C et al (eds) Microbial ecotoxicology. Springer International Publishing AG, Cham, pp 313-336

Hill MK (2004) Understanding environmental pollution. A primer. Cambridge University Press, Cambridge

Hou Q, Ma A, Wang T et al (2015) Detection of bioavailable cadmium, lead and arsenic in polluted soil by tailored multiple Escherichia coli whole-cell sensor set. Anal Bioanal Chem 407:6865-6871

Hu Q, Li L, Wang Y et al (2010) Construction of WCB-11: a novel phiYFP arsenic-resistant wholecell biosensor. J Environ Sci 22:1469-1474

Huang CW, Yang SH, Sun MW et al (2015) Development of a set of bacterial biosensors for simultaneously detecting arsenic and mercury in groundwater. Environ Sci Pollut Res Int 22:10206-10213

Huse SM, Welch DM, Morrison HG et al (2010) Ironing out the wrinkles in the rare biosphere through improved OUT clustering. Environ Microbiol 12:1889-1898

Ilangovan R, Daniel D, Krastanov A et al (2006) Enzyme based biosensor for heavy metal ions determination. Biotechnol Equip 20:184-189

Ivask A, Rolova T, Kahru A (2009) A suite of recombinant luminescent bacterial strains for the quantification of bioavailable heavy metals and toxicity testing. BMC Biotechnol 9:41. https:// doi.org/10.1186/1472-6750-9-41

Jia X, Bur R, Zhao T et al (2019) Development of a sensitive and specific whole-cell biosensor for arsenic detection. Appl Environ Microbiol 85:e00694

Jouanneau S, Durand MJ, Assaf A et al (2017) Bacterial bioreporter applications in ecotoxicology: concepts and practical approach. In: Cravo-Laureau $\mathrm{C}$ et al (eds) Microbial ecotoxicology. Springer International Publishing AG, Cham, pp 283-311

Jung Y, Park C-B, Kim Y et al (2015) Application of multi-species microbial bioassay to assess the effects of engineered nanoparticles in the aquatic environment; potential of a luminous microbial array for toxicity risk assessment (LumiRAMA) on testing for surface-coated silver nanoparticles. Int J Environ Res Public Health 12:8172-8186

Kallmeyer J, Pockalny R, Adhikari RR et al (2012) Global distribution of microbial abundance and biomass in subseafloor sediment. PNAS 109:16213-16216

Kang Y, Lee W, Kim S (2018) Enhancing the Cu-sensing capability of E. coli-based WCB by genetic engineering. Appl Microbiol Biotechnol 102:1513-1521

Kim HJ, Lim JW, Jeong H et al (2016) Development of a highly specific and sensitive cadmium and lead microbial biosensor using synthetic CadC-T7 genetic circuitry. Biosens Bioelectron 79:701-708

Kröger S, Law RJ (2005) Biosensors for marine applications. We all need the sea, but does the sea need biosensors? Biosens Bioelectron 20:1903-1913

Kumar J, D'souza SF (2010) An optical microbial for detection of methyl parathion using Sphingomonas sp. immobilized on microplate as a reusable biocomponent. Biosens Bioelectron 26:1292-1296

Lee S, Sode K, Nakanishi K et al (1992) A novel microbial sensor using luminous bacteria. Biosens Bioelectron 7:273-277

Lehmann M, Riedel K, Adler K et al (2000) Amperometric measurement of copper ions with a deputy substrate using a novel Saccharomyces cerevisiae sensor. Biosens Bioelectron 15:211-219

Lei Y, Mulchandani P, Chen W et al (2007) Biosensor for direct determination of Fenitrothion and EPN using recombinant Pseudomonas putida js444 with surface-expressed organophosphorous hydrolase. 2. Modified carbon paste electrode. Appl Biochem Biotechnol 136:243-250

Leonard SS, Harris GK, Shi X (2004) Metal-induced oxidative stress and signal transduction. Free Radic Biol Med 37(12):1921-1942

Leth S, Maltoni S, Simkus R et al (2002) Engineered bacteria based biosensors for monitoring bioavailable heavy metals. Electroanalysis 14:35-42 
Li L, Liang J, Hong W et al (2015) Evolved bacterial biosensor for arsenite detection in environmental water. Environ Sci Technol 49:6149-6155

Lünse CE, Schmidt MS, Wittmann V (2011) Carba-sugars activate the glmS-riboswitch of Staphylococcus aureus. ACS Chem Biol 6:675-678

Machtel P, Bakowska-Zywicka K, Zywicki M (2016) Emerging applications of riboswitches-from antibacterial targets to molecular tools. J Appl Genet 57:531-541

Magrisso S, Erel Y, Belkin S (2008) Microbial reporter of metal bioavailability. Microb Biotechnol $1: 320-330$

Martin-Betancor K, Rodea-Palomares I, Muñoz-Martín MA (2015) Construction of a self-luminescent cyanobacterial bioreporter that detects a broad range of bioavailable heavy metals in aquatic environment. Front Microbiol 6:186. https://doi.org/10.3389/fmicb.2015.00186

Martin-Gonzalez A, Diaz S, Jareño C et al (1999) The use of protists in ecotoxicology. Recent Res Dev Microbiol 3:93-111

McCown PJ, Corbino KA, Stav S (2017) Riboswitch diversity and distribution. RNA 23:995-1011

Mergeay M, Monchy S, Vallaeys T et al (2003) Ralstonia metallidurans, a bacterium specifically adapted to toxic metals: towards a catalogue of metal-responsive genes. FEMS Microbiol Rev 27:385-410

Merulla D, van der Meer JR (2016) Regulatable and modulable background expression control in prokaryotic synthetic circuits by auxiliary repressor binding sites. ACS Synth Biol 5:36-45

Metha J, Bhardwaj SK, Bhardwaj N et al (2016) Progress in the biosensing techniques for trace level heavy metals. Biotechnol Adv 34:47-60

Nguyen-Ngoc H, Durrieu C, Tran-Minh C (2009) Synchronous-scan fluorescence of algal cells for toxicology of heavy metals and herbicides. Ecotoxicol Environ Saf 72:316-320

Niazi JH, Kim BC, Ahn J-M et al (2008) A novel bioluminescent bacterial biosensor using the highly specific oxidative stress-inducible pgi gene. Biosens Bioelectron 24:670-675

Park JN, Sohn MJ, Oh DB (2007) Identification of the cadmium-inducible Hansenula polymorpha SEO1 gene promoter by transcriptome analysis and its application to whole-cell heavy-metal detection systems. Appl Environ Microbiol 73:5990-6000

Peña-Vazquez E, Perez-Conde C, Costas E et al (2010) Development of a microalgal PAM test method for $\mathrm{Cu}(\mathrm{II})$ in waters: comparison of using spectrofluorometry. Ecotoxicology 19:1059-1065

Peñuelas J, Fillela I (2002) Metal pollution in Spanish terrestrial ecosystems during the twentieth century. Chemosphere 46:501-505

Prathap MUA, Chaurasia AK, Sawant SN et al (2012) Polyaniline-based highly sensitive biosensor for selective detection of lindane. Anal Chem 15:6672-6678

Preveral S, Brutesco C, Descamps EC et al (2017) A bioluminescent arsenite biosensor designed for inline water analyzer. Environ Sci Pollut Res Int 24:25-32

Radhika V, Milkevitch M, Audigé Vet al (2005) Engineered Saccharomyces cerevisiae strain BioS1 , for the detection of water-borne toxic metal contaminants. Biotechnol Bioeng 90:29-35

Ravikumar S, Yoo IK, Lee SY et al (2011) Construction of cooper removing bacteria through the integration of two-component system and cell surface display. Appl Biochem Biotechnol 165:1674-1681

Ravikumar S, Baylon MG, Park SJ (2017) Engineered microbial biosensors based on bacterial twocomponent systems as synthetic biotechnology platforms in bioremediation and biorefinery. Microb Cell Factories 16:62. https://doi.org/10.1186/s12934-017-0675-z

Roda A, Roda B, Cevenini L (2011) Analytical strategies for improving the robustness and reproducibility of bioluminescent microbial bioreporters. Anal Bioanal Chem 401:201-211

Samphao A, Rerkchai H, Jitcharoen J et al (2012) Indirect determination of mercury by inhibition of glucose oxidase immobilizated on carbon paste electrode. Int J Electrochem 7:1001-1010

Serganov A, Nudler E (2013) A decade of riboswitches. Cell 152:17-24

Shahsavari E, Aburto-Medina A, Khudur LD et al (2017) From microbial ecology to microbial ecotoxicology. In: Cravo-Laureau C et al (eds) Microbial ecotoxicology. Springer International Publishing AG, Cham, pp 17-38 
Sharma P, Asad S, Ali A (2013) Bioluminescent bioreporter for assessment of arsenic contamination in water samples of India. J Biosci 38:251-258

Shetty RS, Deo SK, Liu Y et al (2004) Fluorescence-based sensing system for copper using genetically engineered living yeast cells. Biotechnol Bioeng 88:664-670

Shing WL, Surif S, Heng LY (2008) Toxicity biosensor for the evaluation of cadmium toxicity based on photosynthetic behavior of cyanobacteria Anabaena torulosa. Asian J Biochem 3:162-168

Shitanda I, Takada K, Sakai Y et al (2005) Amperometric biosensing systems based on motility and gravitaxis of flagellate algae for aquatic risk assessment. Anal Chem 77:6715-6718

Sperling L, Dessen P, Zagulski M et al (2002) Random sequencing of paramecium somatic DNA. Eukaryot Cell 1:341-352

Tag K, Riedel K, Bauer HJ et al (2007) Amperometric detection of $\mathrm{Cu}^{2+}$ by yeast biosensors using flow injection analysis (FIA). Sens Act B Chem 122:403-409

Tauriainen S, Karp M, Chang W et al (1998) Luminescent bacterial sensor for cadmium and lead. Biosens Bioelectron 13:931-938

Terziyska A, Waltschewa L, Venkov P (2000) A new sensitive test based on yeast cells for studying environmental pollution. Environ Pollut 109:43-52

Tibazarwa C, Wuertz S, Mergeay M et al (2000) Regulation of the $c n r$ cobalt and nickel resistance determinant of Ralstonia eutropha (Alcaligenes eutrophus) CH34. J Bacteriol 182:1399-1409

Tibazarwa C, Corbisier P, Mench $\mathrm{M}$ et al (2001) A microbial biosensor to predict bioavailable nickel in soil and its transfer to plants. Environ Pollut 113:19-26

Tseng H-W, Tsai Y-J, Yen J-H, Chen P-H et al (2014) A fluorescence-based microbial sensor for the selective detection of gold. Chem Commun 50:1735-1737

Valko M, Morris H, Cronin MT (2005) Metals, toxicity and oxidative stress. Curr Med Chem 12:1161-1208

Van der Meer JR, Belkin S (2010) Where microbiology meets microengineering: design and application of reporter bacteria. Nat Rev Microbiol 8:511-522

Verma N, Singh M (2005) Biosensors for heavy metals. Biometals 18:121-129

Vopálenská I, Váchová L, Palková Z (2015) New biosensor for detection of copper ions in water based on immobilized genetically modified yeast cells. Biosens Bioelectron 72:160-167

Walmsley RM, Keenan P (2000) The eukaryotic alternative: advantages of using yeasts in place of bacteria in microbial biosensor development. Biotechnol Bioprocess Eng 5:387-394

Wan X, Ho T, Wang B (2019a) Engineering prokaryote synthetic biology biosensors. In: Handbook of cell biosensors. Springer Nature. https://doi.org/10-1007/978-3-319-47405-2_131-1

Wan X, Volpetti F, Petrova E, French C, Maerkl SJ, Wang B (2019b) Cascaded amplifying circuits enable ultrasensitive cellular sensors for toxic metals. Nat Chem Biol 15:540-548

Wang B, Buck M (2014) Rapid engineering of versatile molecular logic gates using heterologous genetic transcriptional modules. Chem Commun 50:11642-11644

Wang B, Barahona N, Buck M (2013) A modular cell-based biosensor using engineered genetic logic circuits to detect and integrate multiple environmental signals. Biosens Bioelectron 40:368-376

Wang B, Barahona N, Buck M (2014) Engineering modular and tunable genetic amplifiers for scaling transcriptional signals in cascaded gene networks. Nucleic Acids Res 42:9484-9492

Wang B, Barahona N, Buck M (2015) Amplification of small molecule-inducible gene expression via tuning of intracellular receptor densities. Nucleic Acids Res 43:1955-1964

Webster DP, TerAvest MA, Doud DF et al (2014) An arsenic-specific biosensor with genetically engineered Shewanella oneidensis in a bioelectrochemical system. Biosens Bioelectron 62:320-324

Wedekind JE, Dutta D, Belashov IA et al (2017) Metalloriboswitches: RNA-based inorganic ion sensors that regulate genes. J Biol Chem 292:9441-9450

Wong LS, Lee YH, Surif S (2013) Whole cell biosensor using Anabaena torulosa with optical transduction for environmental toxicity evaluation. J Sens 567272:1. https://doi.org/10.1155/ $2013 / 567272$ 
Yagi K (2007) Applications of whole-cell bacterial sensors in biotechnology and environmental science. Appl Microbiol Biotechnol 73:1251-1258

Yoon KP, Misra TK, Silver S (1991) Regulation of the cadA cadmium resistance determinant of Staphylococcus aureus plasmid pI258. J Bacteriol 173:7643-7649

Yoon Y, Kim S, Chae Y (2016a) Simultaneous detection of bioavailable As and Cd in contamined soils using dual-sensing bioreporters. Appl Microbiol Biotechnol 100:3713-3722

Yoon Y, Kim S, Chae Y (2016b) Evaluation of bioavailable Ar and remediation performance using a WCB. Sci Total Environ 547:125-131

Zhou T, Han H, Liu P et al (2017) Microbial fuels cell-based biosensor for toxicity detection: a review. Sensors 17:2230. https://doi.org/10.3390/s17102230

Zorawski M, Shaffer J, Velasquez E et al (2016) Creating a riboswitch-based whole-cell biosensor for bisphenol A. FASEB. https://doi.org/10.1096/fasebj.30.1.supplement.805.3

Zylstra GJ, McCombie WR, Gibson DT et al (1988) Toluene degradation by Pseudomonas putida F1: genetic organization of the tod operon. Appl Environ Microbiol 54:1498-1503 